\title{
The Assessment and Treatment of Post-Abortion Syndrome: A Systematic Case Study From Southern Africa
}

\author{
Melissa Boulind \\ David Edwards \\ Rhodes University
}

Address correspondence to Professor David Edwards, Department of Psychology, Rhodes University, Grahamstown, 6140, South Africa. E-mail: d.edwards@ru.ac.za.

This article reports a clinical case study of "Grace", a black Zimbabwean woman with post-abortion syndrome (PAS), a form of post-traumatic stress disorder precipitated by aborting an unwanted pregnancy. She was treated by a middle class white South African trainee Clinical Psychologist. The case narrative documents the assessment and the course of treatment which was guided by ongoing case formulation based on current evidence-based models. Factors that made her vulnerable to developing PTSD included active suppression of the memory of the event and lack of social support. An understanding of these factors was used to guide an effective intervention. In spite of the differences in culture and background between client and therapist, there was considerable commonality in their experience as young women and students who each had to balance personal and occupational priorities. The narrative also highlights the commonalities of Grace's experiences with those reported in the literature on post-abortion syndrome, which is mostly from the U. S. A. and Europe.

Keywords: Abortion, case study, cognitive-behaviour therapy, depression, post-abortion adjustment, posttraumatic stress disorder, Southern Africa

\section{Case Context}

The legalization of abortion in South Africa in 1997 led to a marked decline in death and serious illness caused by illegal abortions (Jewkes, Brown, Dickson-Tetteh, Levin, \& Rees, 2002; Jewkes \& Rees, 2005). However, assessing the psychological impact of having an abortion is more complex and there is little research from the African continent. Facing an unwanted pregnancy and whether to terminate it or give birth to the baby is a significantly stressful predicament (Coleman, Reardon, Strahan, \& Cougle, 2005; Herman, 2001). Although research suggests that for most women the impact of terminating a pregnancy is largely benign (Adler, et al, 1992), for at least some, it may precipitate post-abortion syndrome (PAS) (Speckhard \& Rue, 1992), a form of post-traumatic stress disorder (PTSD).

\section{Rationale for selecting this client for study}

The present study throws light on a number of factors relevant to this by offering a clinical description of PAS in a black Southern African student situated within an account of her family and social circumstances and documenting an effective therapeutic approach based on current treatments for PTSD and unresolved bereavement. Grace, a Zimbabwean completing a postgraduate degree at a South African University, presented with depression at a Health Centre in April, at the start of the second term. She was assessed and treated by the first author a South African white woman, then a trainee Clinical Psychologist, supervised by the second author, a South African white man. Two assessment sessions yielded only a limited understanding of the source of her depression. However in the next session she disclosed an abortion she had had a few months earlier and it became apparent that this had precipitated her clinical symptoms.
Case-based research has provided evidence that "while abortion may be an effective short-term coping strategy, it may also function as an insidious long-term stressor (Coleman, et al, 2005, p. 252), but there are few comprehensive case descriptions of PTSD precipitated by abortion. Systematic case studies play an important role in the scientific development of clinical theory and practice (Edwards, Dattilio, \& Bromley, 2004; Edwards, 2007; Goodheart, 2005, 2006) and the present case study complements the existing literature by describing the treatment of a case of PAS.

\section{Method}

\section{Clinical case study methodology}

Fishman (2005), editor of the on-line journal Pragmatic Case Studies in Psychotherapy, provided criteria for the conduct and reporting of clinical case studies which can contribute to the science of psychotherapy and his recommendations have been followed here. A thoroughly documented assessment should serve as the basis for a case formulation which, in turn, should provide the foundation for treatment planning. The formulation is a qualitative research step, in that it involves organizing and interpreting a body of data based on established principles. It incorporates working hypotheses about the sources of a client's problems (Sim, Gwee, \& Bateman, 2005) and, in cognitive-behaviour therapy, focuses on factors maintaining the client's distress or dysfunction (Persons \& Tompkins, 1997; Westbrook, Kennerley, \& Kirk, 2007). The formulation, in turn, provides the basis for a treatment plan. The client's response to the treatment serves as a test of the formulation as well as of the clinical theory and practice within which it is founded. 
The construction of a case narrative from the data of the sessions is another qualitative research step. Careful use of tape recordings and session summaries can guard against the narrative being selectively biased towards a particular interpretation of the material (Edwards, et al, 2004). Progress is monitored by regular administration of self-report scales and the data from all these provides an account of how the presenting problems are contextualized within the broader psychological and practical aspects of the client's life and of the ongoing process as therapy unfolded.

\section{Sources of data and quality control}

The narrative of the assessment and treatment was designed to reflect accurately key features of Grace's experience as it unfolded from session to session (see Karpelowsky \& Edwards, 2005). It was written from the perspective of the therapist, the first author, referred to in the first person. Several sources of information complemented each other and served as the basis for this narrative and for the summary of self-report scores to be presented later:

1. Intake interviews: Three tape-recorded assessment interviews followed the assessment procedure of the Health Centre. Information about current presenting problems and developmental and family history was summarized in a standard assessment report.

2. Session records: The nine treatment sessions were tape-recorded and detailed session summaries were made after each.

3. Follow-up: Three months after termination, the therapist phoned Grace and asked questions about her current psychological status.

4. Self-Report Scales: Two 21-item self-report scales were administered at each assessment and therapy session excep the last. The Beck Depression Inventory II (BDI-II) (Beck, Steer, \& Brown, 1996) measures symptoms of depression as described in the DSM-IV (American Psychiatric Association, 2000). The Beck Anxiety Inventory (BAI) (Beck \& Steer, 1993) measures symptoms of panic and generalized anxiety that appear in the DSM-IV. Both have been widely used in South Africa in English and in translation (Steele \& Edwards, 2008).

5. Supervision: The case was presented to a weekly group supervision which focussed on application of current cognitive therapy models. Case formulation and planning of interventions was ongoing and based on close examination of and theoretica reflection on the case material.

\section{Ethical aspects}

Ethical guidelines at the Health Centre apply to treatment and clinical research and were strictly followed. Grace gave written permission for the sessions to be recorded and for the case material to be used for research purposes as a case study. Throughout the therapy Grace reported being pleased that her story might be of value to others and reiterated this during the follow-up phone call. The narrative excludes identifying information and original names, except for those of the authors.

\section{Background Information and Psychological Assessment}

\section{Depression and anxiety}

An attractive 22-year old black woman of medium build and height, Grace was neatly but casually dressed and wore little make up. She appeared composed, though rather nervous and unsure what to expect. Her BDI-II score of 22 (23 at session 2) indicated moderate clinical depression. She had been feeling depressed since returning to University in January, but this had intensified in the past three weeks. She reported headaches, increasing difficulty in concentrating and making decisions, had withdrawn socially, was self-critical and had been losing weight. The death of a close friend during the previous vacation troubled her. The previous term, Grace had suggested they go together for HIV testing. Grace's test was negative but her friend tested positive. Grace believed that learning this had led her friend to lose hope and thus shortened her life. They returned to their respective homes for the Easter vacation and her friend died there. Grace travelled 14 hours to attend the funeral and meet the family. However, she felt burdened by guilt, believing she was responsible for her friend's death. On returning to university, she discovered that her friend's boyfriend was already dating someone else. She felt betrayed and angry and expressed that she hated him.

Although an African, Grace's first language was English. This language was spoken at home and she attended English-speaking schools. While she was as an infant her parents were so poor they did not always have the money to buy milk, but they worked hard to support their four children. Twelve years previously, her father had died of AIDS. Her mother, who had worked in a care-giving role in her youth, had no formal training and was now HIV+ and symptomatic with AIDS. Grace loved and cared for her but was frustrated that she refused to accept anti-retroviral treatment. She was a traditional woman who wanted Grace to be more traditional in outlook. Grace felt jealous of her older sister who was closer to their mother, as she shared her traditionalism. An older brother was living in the U.S. A. and financing her studies. Another brother was irresponsible and not self-supporting and she felt she should try to assist him financially. She felt stressed about the arrangements for her wedding which was due towards the end of the year.

She sought therapy after experiencing a panic attack a few days earlier, as she stood in her kitchen thinking about her upcoming wedding. She had initially completed a BAI with a score of 30 . When asked to use it to record the panic symptoms, her score of 50 indicated that it was indeed a panic attack and it is this that is displayed in Figure 1. In session 2, her BDI was lower (17 - moderate). Despite the intensity of her distress, she believed she should not burden her family or friends with her problems. Her goals for therapy were: (1) Not to be so hard on myself (less self-critical), (2) Not to depend on others' approval, (3) To eat more healthily, (4) To develop a more positive outlook, and (5) To worry less about my academic work.

\section{Session 3: The abortion}

Although exacerbated by her friend's death, her depressive symptoms seemed to have started earlier, so I began session 3 by asking her in detail about the symptoms reported on the BDI-II and BAI. As each was discussed, it became clear that most had started in January. When asked whether something upsetting had happened at that time, she disclosed that she had had an abortion. In December, a few days before returning home for the summer vacation, she had discovered she was pregnant by her fiancé, Chuma, who worked for a financial organization in Zimbabwe. They had met at a family gathering and had been friends for eighteen months before they began dating. $\mathrm{He}$ had visited her towards the end of the previous year, and, despite their use of condoms, she had fallen pregnant. Once she realized this she had briefly discussed options with him tele- 
phonically. However, he did not actively offer his own views and, when she suggested she have an abortion, expressed no disagreement. She mentioned nothing to her family, believing they would be disappointed in her and that it was unfair to burden them with her problems. She also expected that her mother, as a very traditional woman, would have insisted she carry the pregnancy to term. In January, she returned to South Africa, having explained that she needed to write a supplementary examination.

Initially, Grace had not mentioned the abortion for fear that I would be critical of her, but she also seemed unaware that there might be a connection between her depression and the avoided trauma. However, once she had disclosed it, she spoke about it for most of the session. She had felt guilty and had coped by trying not to think about it. Now, she had great difficulty verbalizing her feelings and made the disclosure in an emotionally distant manner. I helped her articulate what it was like to speak about it. She was afraid I would be disappointed in her and felt ashamed, anticipating that others would label her "a slut." Until today only her fiancé had known about the abortion, and he knew nothing about what she had been feeling. She was evidently relieved to be able to speak about it, and, although she remained emotionally distanced, I could see she was anxious as her hands became sweaty and she felt hot. At the end, Grace asked that we re-examine her goals for therapy. She could see that each one was linked to her belief that she was inherently a bad person and a failure and that these thoughts had started to trouble her after having the abortion.

\section{Guiding Conception and Supporting Research}

Following a first-trimester abortion women frequently feel happiness and relief. Adler, et al, (1992) had women rate emotions on scales from 1 (not at all) to 5 (extremely) 2-3 months afterwards. Mean intensity for relief and happiness was 3.96 , markedly higher than the means of 1.81 for socially based negative emotions (shame, guilt, fear of disapproval) and 2.26 for internally based negative emotions (regret, anxiety, depression, doubt, anger). Although they cited research identifying psychological distress associated with termination of pregnancy, the authors concluded that, "in the aggregate, women tend to cope successfully and get on with their lives" (p. 1203). Major, et al, (2000) interviewed over 400 women at the time of having an abortion and at follow-ups. One month afterwards, $79 \%$ expressed satisfaction with the decision to abort, although at two years this had reduced slightly to $72 \%$. Although, at two years, $20 \%$ had reported episodes of clinical depression, the authors claimed that this was the expected rate for women in this age group. $1 \%$ met criteria for PTSD (related to the abortion), which the authors regarded as low considering that as many as $10 \%$ of a normal sample may meet criteria for PTSD. They concluded that "mental health did not decline" (p. 781).

Other research has focused on the negative impact. Reardon and Cougle (2002) and Reardon, et al, (2003) found a higher incidence of psychiatric problems in women who opted for abortion compared to those who carried an unwanted pregnancy to term. These findings have, in turn, been challenged (Schmiege \& Russo, 2005; Major, 2003). Controversy about the mental health impact of abortion is exacerbated by ideologica conflicts (Adler, Ozer, \& Tschann, 2003; Coleman, et al, 2005; Major, 2003; Speckhard \& Rue, 1992). Pro-life advocates may regard abortion as equivalent to the murder of a child, and, in the U. S. A. in particular, bring ongoing challenges to legislation permitting abortion. Pro-choice advocates emphasise the right of women to choose whether to give birth, with all that implies in terms of responsibilities and impact on their lives, and support the legalization of abortion. Research findings can have significant political impact as pro-life advocates may seize on evidence for the negative psychological impact of abortion, while pro-choice advocates may focus on evidence that negative consequences are rare or even non-existent.

Qualitative research and case studies document the significant and enduring distress experienced by some women and show that termination of a pregnancy can be a precipitating factor for psychological disorders, either in the immediate aftermath or as a delayed reaction. Coleman, et al,, (2005) reviewed interview studies in which participants described PTSD symptoms related to having an abortion including a Swedish study in which, one year later, $76 \%$ said they would not consider having an abortion again and $16 \%$ described emotional distress that was either occupationally disabling or led them to seek psychological help. Haynie and Wilson (2007) reviewed studies which found rates of PTSD at two years post abortion to be closer to $20 \%$, and an early series of five cases where symptoms of depression, anxiety and eating disorders were traced to a previous abortion. Speckhard and Rue (1992) reviewed studies that provided clinical descriptions of PTSD symptoms following termination of pregnancy and proposed criteria for PAS as a specific form of PTSD. In Spain, Gomez and Zapata (2005) reported ten cases of PAS which met criteria for PTSD and where symptoms included recurrent nightmares related to the abortion, feelings of guilt, and desire to repair the damage done. Bowles, et al, (2000) drew attention to the occurrence of PTSD in women whose pregnancies terminated as a result of miscarriage.

The few studies from Africa also document some of the psychological distress associated with abortion. South African students rated having an abortion as a significant threat to health, with only HIV/AIDS, road accidents and sexually transmitted diseases being ranked higher (Peltzer, 1999). A study of five women who had had abortions in Gabon, where abortion is illegal, found that although one did not regret it, the others felt guilt, remorse or both. In two cases the male partner was angry when he learned about it (Hess, 2007). In a qualitative study of 5 black South African women who had had illegal abortions all experienced relief, but this was followed by feelings of guilt, shame, regret and grief (Suffla, 1997). In another South African qualitative study, black women seeking abortions identified significant difficulties in finding meaningful social support from family and friends (Geldenhuys \& De Lange, 2001). Faure and Loxton (2003) administered self-report measures at a South African clinic to women about to undergo a first-trimester abortion and to those who returned to the clinic during the following month (about half of the sample). There was evidence for significant distress at the first visit: anxiety was high and about half reported mild to moderate depression. At follow-up, anxiety was considerably lower but $28 \%$ were still depressed. Women with higher self-efficacy had lower anxiety before the abortion and lower depression afterwards and depression before the abortion strongly predicted depression at follow-up.

In the immediate aftermath of abortion, many women focus on survival and coping and numb themselves to negative feelings. It can be several years before suppressed negative feelings break through and, where psychological and behavioural problems emerge later, individuals may not recognize their link to the abortion (Speckhard \& Rue, 1992). Clinically, the symptoms of PAS are similar to those reported after other traumatic events such as rape, assault, motor-vehicle accidents and sur- 
gery. These include flashbacks, emotional numbing, interpersonal distrust, helplessness, sadness, shame, guilt, hopelessness, suicide attempts/suicidal ideation, anniversary reactions, anger and sexual dysfunction. For many, there is grief at the loss of the child who was never born, since many women consciously or unconsciously bond with the foetus (Coleman et al, 2005; Gomez \& Zapata, 2005; Haynie \&Wilson, 2007; Speckhard \& Rue, 1992; Suffla, 1997).

PAS can be treated within current evidence-based approaches to PTSD (Ehlers, Clark, Hackmann, McManus \& Fennel, 2005; Clark \& Ehlers, 2005) and traumatic grief (Shear, Frank, Houck \& Reynolds, 2005). These recognize that, in response to any traumatizing event, there is a range of personal responses and the nature of the accompanying distress varies from individual to individual. Psychological assessment and treatment planning are based on understanding the idiosyncratic presentation of emotional states and personal meanings of each client, identifying obstacles to resolution, and selecting interventions to target them.

\section{Case Formulation and Treatment Plan}

Grace met criteria for Major Depressive Disorder, single episode. She also met criteria for PTSD: she felt upset when reminded of the abortion (re-experiencing), she systematically tried not to think or talk about it, felt less interested in activities, felt detached and estranged from other people (avoidance), and had hyperarousal in the form of sleep difficulties, and other anxiety symptoms recorded on the BAl in the first two sessions (feeling hot, faint, sweating, scared, afraid of dying, nervous, afraid off losing control, unable to relax) as well as at least one intense panic attack. There was no information yet about whether she had found the physical aspects of the medical procedure traumatic, but she had felt conflicted about ending the pregnancy. Because she had coped by thought suppression and avoiding speaking about it, she had been unable to reflect on the event, experience what she really felt, or examine the implications. These are the conditions under which PTSD fails to resolve as the event cannot be incorporated into autobiographical memory (Ehlers \& Clark, 2000; Clark \& Ehlers, 2005).

Yet the abortion and its meaning were of central significance for her life, and her blocking off of thoughts and feelings about it had set her up to develop depression and PTSD. The depression was exacerbated by her friend's death and the associated guilt. These developments were reflected in her goals for therapy. It seemed probable, therefore, that the depression was secondary to the PTSD and that treatment that addressed the PTSD would also address the depression. The aim of the treatment was to help her tell the full story of the abortion and the events leading up to it, to explore the personal meanings associated with loss, shame, guilt and other distressing emotions, and to help her reframe those meanings in a positive direction.

\section{Treatment Narrative}

\section{Session 4}

The disclosure of the abortion provided marked relief. Her symptoms of anxiety and depression remitted after session 3 (see Figures 1 and 2). However, the memory of what had happened was still not integrated. Grace said it was as though it had been placed in a box:

...it's locked away at the back of my mind, and I don't know if I can take it out... I just don't know if I can talk about it...
Following this metaphor, I gently suggested we could work together on bringing the box forward, opening it and taking out what was inside. At the end of each session the box could be closed again, allowing her to get on with her everyday activities. Grace was receptive to this.

She then spoke about how she was pleased that she had greeted somebody at her church. Making conversation had allowed her to feel more connected. She went on to explain that today she was to role play a defense attorney at a trial and described in some detail what she would be saying and wearing. She was to act in the best interests of the client and portray the client's side of the story. At the time, I thought these topics were a means to avoid talking further about what was so threatening. In retrospect, however, they could be interpreted as unconscious communications, letting me know that she was re-engaging with life so that she was no longer in crisis and that she was learning to take an alternative perspective on her situation.

\section{Session 5}

In session 5, Grace described three dreams which portrayed feelings about her impending marriage. In the first, she was wandering in a crowd of people, feeling lost, unsure where to go. There was a woman in a white dress. In the second, she felt very distressed as she wandered around in a wedding dress that was extremely ugly. She was unsure of the way ahead and afraid that others would think that she was ugly. She explained that she had found some materials that she would like to have her dress made with, but it seemed unlikely she could afford what she really wanted. Although not explicit, these dreams suggested that the abortion had cast a shadow over her upcoming wedding. The ugliness portrayed her sense that the beautiful wedding she had been anticipating had been spoilt by her pregnancy and abortion, and that although currently a secret, others would find out about it and she would feel ashamed. She therefore no longer felt there was a clear way forward into the future.

In the third dream she was again wandering in a crowd of people and saw her father. She only recognized who it was when she woke up and was surprised at seeing him in the dream. The dream suggested that her present experiences were coloured by her response to her father's death 12 years before. She remembered him as a kind and humorous man. He had supported the family financially and she felt resentful that, now he was gone, in addition to assisting her mother with tasks like shopping, she had to assist her financially too. Her mother had told her how to save money so she could provide food for her family. Once she started at University, she worked as a waitress and saved money so that she could take food home. In her suitcases she packed only a few personal belongings, and used the remaining space for food, including fruit and vegetables. After their father's death, her eldest brother had taken on the parent role. This changed their relationship so she felt she had lost a brother too, as she could no longer talk to him as she had before. The consequence of all this was that she felt burdened with responsibility for other family members, and without any meaningful emotional support herself.

\section{Session 6}

Grace began by reviewing her goals for therapy and removed several items: depending on others' approval, eating healthily, having a positive outlook, and not worrying about her academic work. With the remission of her depression, these problems had remitted as she was able to work productively 
and felt more positive about herself and her life. Grace reported that being able to talk to someone about her problems had allowed her to let go of many things, such as disputes with her friends and wanting to change others' behaviour. Much of the session focused on another factor that had contributed to her social isolation. Grace was a committed Christian and her main social support had been through a local church. However, the church was authoritarian and prescriptive and all intimate relationships had to be approved by the pastor. As Grace's fiancé did not attend church regularly, the pastor, supported by her friends, instructed Grace to end the relationship. In September the previous year, Grace had stopped attending church and lost her social support. She missed her friends, the feeling of belonging to a community/family, and having people to share activities with and talk to. Although she started attending another church, she was reluctant to get involved in church activities or confide in people in case the same happened again.

\section{Session 7}

These sessions, in which Grace had identified how isolated she had become both from family and friends, seemed to clear the way for her to use the support offered by the therapy. Although she arrived ten minutes late, she initiated session 7 assertively, in a way she had not done before, saying she was ready to talk about the abortion. In supervision, I had expressed concern that Grace might become overwhelmed and it was decided that I would suggest we break the process into those parts that would be easier to talk about and those that would be most difficult. Grace said that the easiest thing to talk about would be how she found out she was pregnant, then the decision-making process, then the abortion itself, and finally the aftermath. For the remainder of the session, Grace spoke about the first of these.

In an emotionally detached manner, she told how, following her break with the church, her fiancé had visited her for 2 weeks, to support her and strengthen the relationship. Afterwards, she became concerned when her period was 3 weeks overdue, but, because she was usually quite irregular, she did not worry too much. However, she also experienced abdominal pains and nausea and when, after six weeks, she still had not menstruated, she bought a home pregnancy test. She felt embarrassed obtaining it, afraid the shop assistant would question her. She confided in no-one and did the test alone in her bathroom. When the test was positive, she bought another test just to be sure. Again the result was positive. She would soon be returning home for the vacation. She phoned Chuma who sounded surprised but did not ask any questions. She said they could discuss it further once she was home. The tone of irritation in her voice showed how angry she still felt about having to deal with this alone. For the next few days the pregnancy was all she could think about. When she phoned Chuma and suggested they consider that she have an abortion, he did not really discuss it or actively dissuade her. She booked the abortion at the local hospital before returning home.

\section{Session 8}

At the end of the previous session, Grace had expressed disappointment with herself as she felt she had rushed into the decision without fully thinking it through. In supervision it was recommended that time be spent on her decision to have the abortion and the options she might have considered had she had proper social support at the time. It transpired that although she had not been able to talk it over with anyone, she had been aware of the likely outcomes of the different courses of action open to her. If she had given birth to the baby, she would have had to drop her degree, and probably sacrifice her career. She believed that she would lose everything she had worked hard to achieve. She could marry Chuma and they could raise the child together, but, with only one parent working, she was afraid she would not be able to provide the quality of life to which she aspired. The situation would be no better if she did not marry Chuma. She would probably have less financial support and the added difficulty of raising an illegitimate child. Either way, she feared that giving up her career might lead her to resent the child. Another option was to have the baby and give it up for adoption. This also was unattractive. She would have the inconvenience of carrying the child to term and believed she would have to give up completing her degree. She would also have to suffer the humiliation of letting her family know about the pregnancy.

In previous sessions, Grace had shown little or no emotion. Now, by contrast, she became increasingly agitated as she reflected on these options. She expressed anger with Chuma for not contributing to the decision making process. Although he had offered his support, he had never expressed his own opinion, so she had no idea what he wanted. "He left me to make the decision alone... the biggest decision of my life and there was no-one!" she exclaimed. Her isolation and lack of support had been a repetitive theme in most of the previous sessions. Now, at last she connected with it experientially and for the first time wept openly, expressing the pain of having been through so much all on her own. As her emotion subsided, Grace recognized that at the time she had not acted hastily or impulsively. She had been aware of the options and of the pros and cons of each. She had chosen what she believed was the best option for her and would probably do the same again were she in the same predicament now.

\section{Session 9}

In supervision, it was agreed that it would help Grace to re-experience the trauma of the abortion itself with my support, so that she could have the space to identify all her different emotions, have her experiences validated, and process any unresolved emotions. Grace arrived 10 minutes late. She knew that the plan was to look at the abortion experience. However, she was currently writing exams and described how the exams were going in each of her courses. I reflected that she knew today's session was going to be difficult as she would be speaking about something that she had not spoken about before, and had wanted to forget. Grace became slightly tearful. I reviewed how she had experienced the previous session. She said that it had felt good to go through things and discuss them. She then began to describe her experiences on the day of the abortion itself.

She awoke, feeling as if she had not slept at all.

I ... felt so alone... it's the most alone that I have ever felt. Nobody knew where I was going, I hadn't told anyone. Chuma tried to call me and I couldn't even answer the phone...

In the hospital waiting room she tried to read but could not take anything in. What was probably a 45 minute wait seemed like hours. She was taken to a private room, which evoked a feeling of shame that she was being hidden away because she was doing something wrong. There was a female doctor and some nurses who all seemed supportive and gave her tablets to drink. She was surprised that no one asked her any questions or tried to talk her out of it. She became very distressed as she told 
how the doctor had told her to lie down and relax. How could she relax? Her stomach was in a knot and she felt cold. She felt detached as if this was all happening to someone else. Gradually she experienced stomach cramps and then began bleeding. The bleeding and the sight of blood appeared to have had the most impact on her. A lot of time was spent on her description of this. She felt numb and guilty.

I remember the blood ... there was so much of it... I remember being worried that somebody else had to clean it up, it felt like it was everywhere....

A few hours later she went home, locked herself in her room and cried for what felt like hours, until she fell asleep. Much of her distress centred round her sense of abandonment and isolation: "Nobody knew... and nobody cared!" After that, Grace explained, "I tried to continue as though it had never happened... I thought that I could forget about it". She continued with her studies and she and Chuma continued with their relationship (at long distance). The abortion was never discussed.

\section{Session 10}

The next session would be followed by the four week July vacation. I suggested that Grace needed to work towards two goals. First she needed to mourn for her lost baby. Second she needed to accept and come to terms with all that it had meant to her so that she could incorporate the experience of the abortion into her past experience. Grace volunteered that in order to move forward she needed to share with Chuma how she had reached the decision and what her experience had been. "He needs to know how alone I felt... and how scared I was...," she said. She believed that when they had spoken about this, they could decide together how to mourn for the lost baby. She would soon be seeing him again but was unsure how to initiate such a conversation. We discussed different options. Grace suggested she could begin by thanking Chuma for being there for her and asking him how he had felt about the abortion. Time was spent role-playing what she wanted to tell him.

\section{Sessions 11-12 and follow-up}

At the beginning of the next term, Grace was evidently happy as she described how she and Chuma had spoken in great depth about the abortion. They had discussed the decision making process, her experience in hospital, and her anger that he was not there when she needed him. Chuma had offered his support for her decision and they discussed how their lives might have been different if she had gone ahead with having the child. They would have married earlier than intended. She would not have completed her degree as the pregnancy would have interfered with her studies and having a young child would have made it impossible for her to complete her further training. Although Chuma was willing to support her, she wanted to contribute to the household expenses herself and did not want to be completely dependent on him financially. Chuma had expressed the concern that she might have been marrying him just because of having the baby and not because she really wanted to be married to him.

Grace indicated that she had effectively dealt with the problems she had come for help with and was ready to terminate the therapy. She believed that she had grown as a person and could now deal with her life on her own. She was no longer so socially isolated as she had made new friends at her church. I stressed the importance of sharing her thoughts and feelings with her friends and fiancé. It was agreed that there would be a further session, and that, in preparation, Grace would make a collage of her journey through the therapy process.

Grace brought the collage to the final session. Among the many pictures she had used were two babies. "One is the one which was never born ... and the other is the baby which I am still going to have..." There was also a picture of a well dressed woman holding a pile of books, which portrayed her having completed her degree, and another of a woman smiling, which portrayed the happiness she was feeling now.

Three months later, I phoned Grace to find out how she was. She reported no residual symptoms of depression or anxiety. She and Chuma had set a date for the wedding and their relationship was progressing well. She also reported that her interpersonal relationships were improving. She felt optimistic about working the following year and had sent out job applications to a number of firms.

\section{Monitoring: Graphical Presentation of Repeated Measures}

Grace completed the BAI and BDI-II at every session except the last. Her scores are displayed graphically in Figures 1 and 2. What is remarkable is that both BAI and BDI scores dropped completely after her disclosure of the abortion in the third session. Even though there was still a great deal of work to do to process what had happened to her, she no longer experienced debilitating symptoms of depression or had further panic attacks and no longer met criteria for any mental disorder.

\section{Discussion and Conclusions}

Case studies complement findings from other forms of research (Edwards, 2007) and address "the need for more diversified research strategies" (Coleman et al, 2005, p. 249). The narrative provides insight into one person's experience of facing the decision to terminate an unwanted pregnancy within a particular context of economic and family life in Southern Africa. Many of its themes are widely experienced: the economic hardship caused by a father's death, the reality of HIV/AIDS, the commitment to education as a route to a better life and the suppression of traumatic memories. Thus one of Suffla's (1997, p. 221) informants remarked "I was at university and if I had this

\section{Figure 1. Grace's BAI Scores}

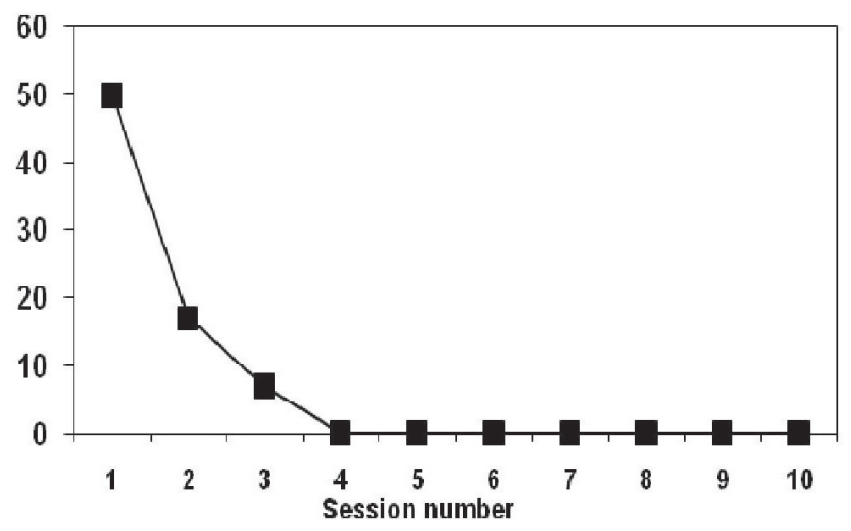


Figure 2. Grace's BDI-II Scores

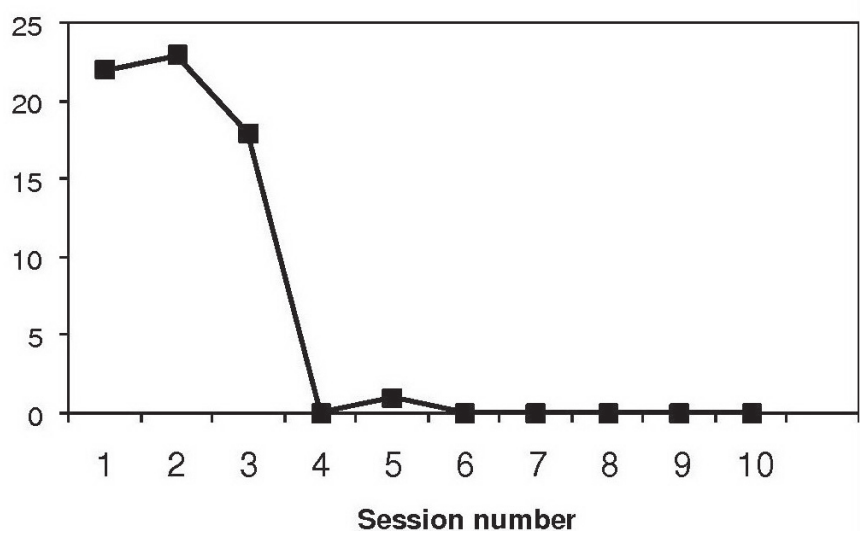

baby I would not have been able to complete my studies" and another said, "I suppressed all the hurt. I didn't want to think about it ... I threw myself into my studies ... I realized I hadn't been dealing with my feelings properly."

Despite the differences in cultural experience between therapist and client, there were commonalities which enabled them to form an effective working alliance. A relationship developed between two young women with a common language, and status as students, one of whom had had an abortion, and the other who was assisting her to talk and explore her thoughts and feelings about it. Marked cultural differences in beliefs and practices (for example attributions of symptoms to witchcraft) may need to be addressed in working with African people (Eagle, 2004). However, in the setting within which this case was treated, similar cases are encountered in which limited attention needs to be given to negotiating cultural differences (e. g. Karpelowsky \& Edwards, 2005), even with less educated clients.

Coleman, et al, (2005) searched for cultural factors that might impact on attitudes to abortion and the only salient one they could identify was the degree of social acceptance of abortion. This, of course, can also vary considerably within a single cultural setting. Grace's Christian affiliation probably contributed to her difficulties since religious commitment is associated with guilt about abortion (Adler, et al, 1992; Coleman, et al, 2005), but many of Grace's attitudes were not conservative and she had rejected her mother's African traditionalism. The therapist, who was raised as a Christian Catholic but was now agnostic had anticipated that the difference in beliefs might impact on the therapy, but in the event Grace's Christian beliefs were not a central focus of therapy.

Several factors contributed to Grace's vulnerability to developing PTSD and depression: her father's death, her break with the church and the recent death of her friend, and cognitive patterns such as her over-responsibility and tendency to blame herself. However, she showed herself to be a resourceful person in the fact that she had not been clinically depressed before, despite the hardships she had faced, and in the way she responded to the assessment and therapy. The rapid remission of her symptoms once she had disclosed the abortion provides evidence that, although her friend's death had exacerbated her depression, it was the abortion that constituted the main precipitating factor for the depression and PTSD.
Grace's PAS was exacerbated by systematic suppression of thoughts and feelings about the trauma, and, as in cases referred to by Speckhard and Rue (1992), she failed to link current symptoms to the abortion itself. This does not mean that abortion is intrinsically psychologically harmful. Adjusting to giving birth following an unplanned pregnancy also poses significant challenges and, on the basis of the case material, no conclusion can be drawn as to which would have been more psychologically problematic for Grace in the long term. What this study shows is that where PAS develops it can be effectively treated. In treatment planning, two goals were kept in balance: building a respectful collaboration with the client and selecting interventions on the basis of the treatment model. Once Grace's symptoms had subsided, a less directive therapist might not have pressed for active engagement with the trauma memory. At the same time, the therapist also respected Grace's own pace and process. Only in session 7 did she begin to share the details of the events leading up to the abortion and only in session 9 did she allow herself to re-experience the painful events of the day of the abortion itself. The narrative suggests that the other sessions were not wasted. In sessions 4 to 6 Grace was disclosing important and difficult experiences and growing from the validation of her feelings. She was also recognizing the extent of her social isolation, its contribution to the intensification of her symptoms, and the importance of rebuilding her connections with others.

Grace's experience illustrates how social isolation increases vulnerability to PTSD. Despite Chuma's commitment and support, his reticence, and the physical distance between them, left Grace isolated. This was exacerbated by her leaving the church, and her belief that she should not burden her family members. To come to terms with a traumatic event and incorporate it as part of one's life story it is important to be able to think through what it means personally and to evaluate these meanings carefully. This process is facilitated by having meaningful and respectful social support (Calhoun \& Tedeschi, 2006). The study also supports Coleman, et al,'s (2005 p. 262) emphasis on the "importance of encouraging women ... to thoughtfully work through the decision and to reach out to others as they explore the pros and cons" and their conclusion that resolution leads to the restoration of self-efficacy. At the end Grace felt able to handle the challenges of her life again, in a way that she could before she became pregnant.

The value of a formulation based approach to intervention is also illustrated. Therapy was guided by the theories of Ehlers and Clark (2000; Clark \& Ehlers, 2005) on PTSD and Shear, et al (2005) on traumatic grief. Given the range and complexity of the psychological factors presented by Grace, many different interventions could have been employed. However, only a small number of the interventions available within these approaches could actually be used. As Grace's accounts of her experiences in the week showed that she was successfully re-engaging with the practical aspects of life, the therapist did not need to introduce structured interventions to facilitate this and could focus on helping her experience the range of feelings she had been suppressing, identifying their meaning and reframing them in a constructive direction.

While the self-report scales indicated relief of symptoms, Grace's metaphor of the memory being "in a box" showed that the event had not yet been processed. The dreams she reported in the next session also pointed to unexpressed emotional turmoil. These observations guided treatment planning and motivated therapist and supervisor to encourage Grace to 
work towards the reliving of the trauma. Once she had done this she completely understood the therapist's suggestion that she needed to work on mourning the lost child and incorporating the events into her life experience and recognized at once that she needed to talk in depth with her fiancé. Although she was unsure how to do this, the role play work was enough to prepare her to engage with him in depth while she was visiting him the following week.

Despite these general conclusions, this is also a unique case. The course of assessment and treatment of other individuals with PAS could be quite different. Although Grace was emotionally estranged from her family members, there was a strong and healthy relationship with her fiancé. In many cases where a pregnancy is unwanted, there may not be a supportive relationship with the man involved and more work may be needed to help the client build meaningful social support. Grace herself was self-motivated, had a vision of her future and was resourceful. The interventions allowed her to use her own resources to direct the process forward. The length of time it takes to treat PTSD or traumatic grief varies considerably (e. g. Gillespie, Duffy, Hackmann, \& Clark, 2002). In less resourceful individuals, therapy could be longer as attention would need to be directed at building resources and finding goals for the future. Therapists treating PAS should not expect to use the case narrative as a treatment manual. However the clinical material of the case, taken in conjunction with a case formulation approach, provides much detail that could throw light on treatment planning with new cases.

\section{References}

Adler, N. E., David, H. P., Major, B. N., Roth, S. H., Russo, N. F., \& Wyatt, G. E. (1992). Psychological factors in abortion: A review. American Psychologist, 47, 1194-1204.

Adler, N. E., Ozer, E. J., \& Tschann, J. (2008). Abortion among adolescents. American Psychologist, 58, 211-217.

American Psychiatric Association (2000). DSM-IV-TR: Diagnostic and statistical manual of mental disorders (fourth edition): Text revision. Washington D.C.: American Psychiatric Association.

Beck, A. T., \& Steer, R. A. (1993). Beck Anxiety Inventory: Manual. San Antonio TX: Psychological Corporation.

Beck, A. T., Steer, R. A., \& Brown, G. K. (1996). Beck Depression Inventory - Second Edition: Manual. San Antonio TX: Psychological Corporation.

Bowles, S. V., Solursh, D. S., Yancey, M. K., Epperly, T. D., Folen, R. A., \& Mason, M. (2000). Acute and posttraumatic stress disorder after spontaneous abortion. American Family Physician, 61, 1698-1696.

Calhoun, L. G., \& Tedeschi, R. G. (2006). The foundations of posttraumatic growth: An expanded framework. In L. G. Calhoun \& R. G. Tedeschi (Eds.), Handbook of posttraumatic growth: Research and practice (pp. 1-23). Mahwah, NJ: Lawrence Erlbaum.

Clark, D. M., \& Ehlers, A. (2005). Posttraumatic stress disorder: From cognitive theory to therapy. In R. L. Leahy (Ed.), Contemporary cognitive therapy (pp. 141-160). New York: Guilford.

Coleman, P. K., Reardon, D. C., Strahan, T., \& Cougle, J. R. (2005). The psychology of abortion: A review and suggestions for future research. Psychology and Health, 20, 237-271.
Eagle, G. T. (2004). Therapy at the cultural interface: Implications of African cosmology for traumatic stress intervention. Psychology in Society, 30, 1-22.

Edwards, D. J. A. (2007). Collaborative versus adversarial stances in scientific discourse: Implications for the role of systematic case studies in the development of evidence-based practice in psychotherapy. Pragmatic Case Studies in Psychotherapy, 3, Module 1, Article 2. 6-24. Available at http://pcsp.libraries.rutgers.edu.

Edwards, D. J. A., Dattilio, F., \& Bromley, D. B. (2004). Developing evidence-based practice: The role of case-based research. Professional Psychology: Research and Practice, 35, 589-597.

Ehlers, A., \& Clark, D. M. (2000). A cognitive model of posttraumatic stress disorder. Behaviour Research and Therapy, 38, 319-345.

Ehlers, A., Clark, D. M., Hackmann, A., McManus, F., \& Fennell, M. (2005). Cognitive therapy for post-traumatic stress disorder: Development and evaluation. Behaviour Research and Therapy, 43, 413-431.

Faure, S., \& Loxton, H. (2003). Anxiety, depression and self-efficacy levels of women undergoing first trimester abortion. South African Journal of Psychology, 33, 28-38.

Fishman, D. B. (2005). Editor's Introduction to PCSP - From Single case to database: A new method for enhancing psychotherapy practice. Pragmatic Case Studies in Psychotherapy [Online], 1, Module 1, Article 2. Available at http://pcsp.libraries.rutgers.edu.

Geldenhuys, J. L., \& de Lange, N. (2001). Black eastern cape adolescents' experience of pregnancy termination. South African Journal of Education, 21, 92-98.

Gomez, L., \& Zapata, G. (2005). Diagnostic categorisation of post-abortion syndrome. Actas Espanolas Psiquiatria, 33, 267-272.

Goodheart, C. D. (2005). Placing psychotherapy case studies within the framework of the APA evidence-based practice in psychology (EBPP) model. Pragmatic Case Studies in Psychotherapy [on line], 1, Module 3, Article 2. Available: http://pcsp.libraries.rutgers.edu.

Goodheart, C. D. (2006). Evidence, endeavour and expertise in psychological practice. In C. D. Goodheart, A. E. Kazdin, \& R. J. Sternberg (Eds.), Evidence-based psychotherapy: Where practice and research meet (pp. 37-63). Washington, DC: American Psychological Association.

Haynie, L., \& Wilson, K. (2007). State of knowledge: Post abortion outcomes. Journal of Health Ethics, 1 (1). Downloaded on 3 August 2008 from http://ethicsjournal.umc.edu/ojs2/index.php/ojhe/issue/view/10

Herman, J. L. (2001). Trauma and recovery: From domestic abuse to political terror. London: Pandora.

Hess, R. F. (2007). Women's stories of abortion in Southern Gabon, Africa. Journal of Transcultural Nursing, 18, 41-48.

Jewkes, R., Brown, H., Dickson-Tetteh, K., Levin, J., \& Rees, H. (2002). Prevalence of morbidity associated with abortion before and after legalisation in South Africa. British Medical Journal, 324, 1252-1253.

Jewkes, R., \& Rees, H. (2005). Dramatic decline in abortion mortality due to the Choice in Termination of Pregnancy Act. South African Medical Journal, 95, 250. 
Karpelowsky, B. J., \& Edwards, D. J. A. (2005). Trauma, imagery and the therapeutic relationship: Langu's story. Journal of Psychology in Africa, 15, 185-195.

Major, B. N. (2003). Psychological implications of abortion highly charged and rife with misleading research. Canadian Medical Association Journal, 168, 314-339.

Major, B. N., Cozzarelli, C., Cooper, M. L., Zubek, J., Richards, C., Wilhite, M. et al. (2000). Psychological responses of women after first trimester abotion. Archives of General Psychiatry, 57, 777-784.

Peltzer, K. (1999). Posttraumatic stress symptoms in a population of rural children in South Africa. Psychological Reports, 85, 646-650.

Persons, J. B., \& Tompkins, M. A. (1997). Cognitive-behavioural case formulation. In T. D. Eells (Ed.), Handbook of psychotherapy case formulation (pp. 314-339). London: Guilford.

Reardon, D. C., \& Cougle, J. R. (2002). Depression and unintended pregnancy in the national longitudinal survey of youth. British Medical Journal, 324, 151-152.

Reardon, D. C., Cougle, J. R., Rue, V. M., Shuping, M. W., Coleman, P. K., \& Ney, P. G. (2003). Psychiatric admissions of low-income women following abortion and childbirth. Canadian Medical Association Journal, 168, 1253-1256.

Schmiege, S., \& Russo, N. (2005). Depression and unwanted first pregnancy: Longitudinal cohort study. British Medical Journal, 331, 1303-1308.

Shear, M. K., Frank, E., Houck, P. R., \& Reynolds III, C. F. (2005). Treatment of complicated grief: A randomized controlled trial. Journal of the American Medical Association, 293, 2601-2608.

Sim, K., Gwee, K., \& Bateman, A. (2005). Case formulation in psychotherapy: Revitalizing its usefulness as a clinical tool. Academic Psychiatry, 29, 289-292.

Speckhard, A., \& Rue, V. (1992). Post Abortion Syndrome: An emerging public health concern. Journal of Social Sciences, 42, 95-114.

Steele, G., \& Edwards, D. J. A. (2008). Development and Validation of the Xhosa Translations of the Beck Inventories: 1. Challenges of the translation process. Journal of Psychology in Africa, 18, 207-216.

Suffla, S. (1997). Experiences of induced abortion among a group of South African women. South African Journal of Psychology, 27, 214-222.

Westbrook, D., Kennerley, H., \& Kirk, J. (2007). An introduction to cognitive behaviour therapy. Los Angeles: Sage.

\section{Author's Note}

Professor David Edwards is a clinical psychologist and Professor in the Psychology Department at Rhodes University in the Eastern Cape, South Africa. Ms. Melissa Boulind is a graduate of the Master's course in Clinical Psychology at Rhodes University's where this study was conducted and is currently Senior Clinical Psychologist at G.J. Crookes Hospital, Umbogintwini, Kwazulu-Natal, South Africa.

\section{Acknowledgements}

This research was supported by a grant from the Rhodes University Joint Research Committee. The authors are grateful to "Grace" for her willingness to share her story in this way. 
